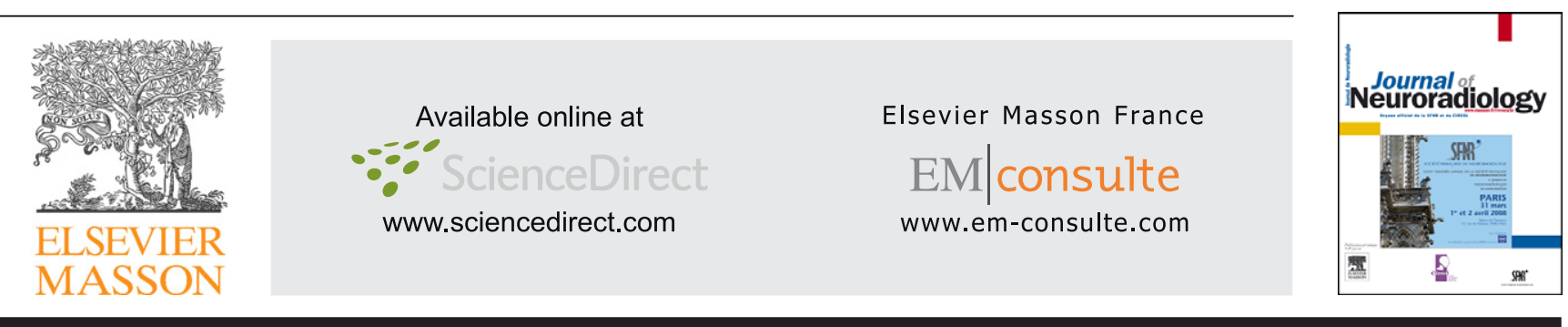

\title{
CORRESPONDENCE
}

\section{Fibromuscular dysplasia with dissecting basilar aneurysm: Endovascular treatment}

\section{Dysplasie fibromusculaire avec anévrysme dis- séquant de l'artère basilaire: traitement endovasculaire}

A 56-year-old woman was admitted to hospital with a Hunt-Hess grade III spontaneous subarachnoid hemorrhage with no focal neurological deficit. Four vessel angiography revealed a midbasilar artery dissecting aneurysm (Fig. 1A) and a "string of beads" appearance of both cervical carotid arteries (not shown), a specific sign of fibromuscular dysplasia (FMD). Posterior cerebral arteries were spared.
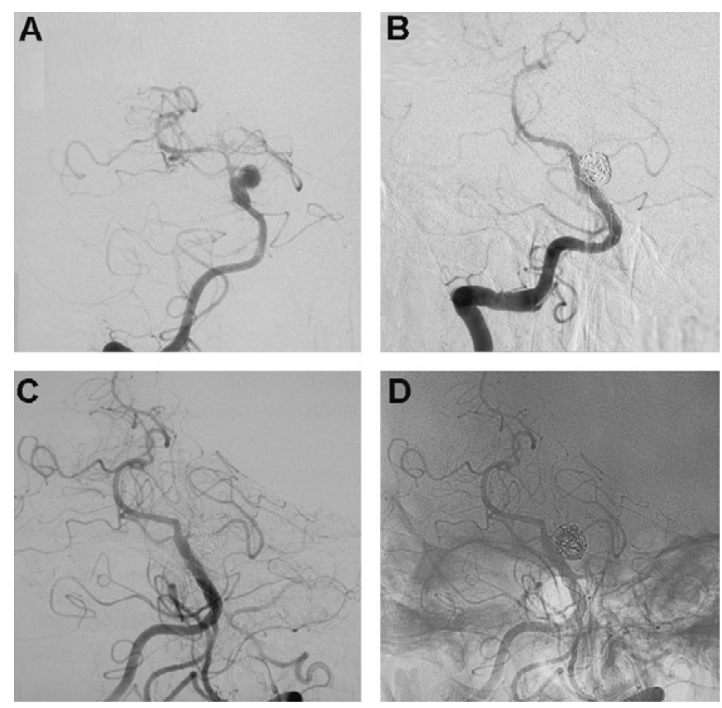

Figure 1 Digital subtraction angiogram: right vertebral artery injection shows the midbasilar fusiform dissecting aneurysm (A). After detachment of the stent and three hydrocoils (B), the aneurysm is occluded and the basilar artery is wide open. At the 6-month follow-up, subtracted (C) and unsubtracted (D) images show that the aneurysm remains occluded with no evidence of in-stent stenosis.
Endovascular treatment was decided upon. The patient received a loading dose of clopidogrel $(300 \mathrm{mg})$, and the procedure was undertaken under general anesthesia and full heparinization. A 6-F guiding catheter (Envoy, Cordis, Miami, $\mathrm{FL}$ ) was placed in the proximal right vertebral artery, and the microcatheter was advanced into the basilar artery using a coaxial system with the help of a microguidewire. After removing the microguidewire, the stent (Leo, Balt, Montmorency, France) was aligned directly across the neck of the aneurysm and detached, covering the diseased segment. This resulted in a patent basilar artery with residual filling of the aneurysm. The microcatheter was then placed inside the aneurysm sac, through the stent mesh, and occlusion was carried out using three hydrocoils.

The final control angiography (Fig. 1B) demonstrated good flow through the stent, with normal filling of the posterior territory and total occlusion of the aneurysm. The patient made an excellent recovery, and was discharged with a treatment regimen of aspirin and clopidogrel daily for 3 months, followed by aspirin alone. Follow-up angiography (Fig. $1 C$ and D) and magnetic resonance imaging (at 6 and 12 months, respectively) showed that the treated pseudoaneurysm remained occluded and that the basilar artery was wide open with no signs of in-stent stenosis.

FMD is a segmental vasculopathy of unknown etiology that typically involves the cervical internal carotid and vertebral arteries and, rarely, the intracranial arteries. The association of FMD with saccular and dissecting aneurysms of the extracranial arteries [1] is well-known, but dissecting aneurysms of the intracranial arteries are rare. In FMD, damage to the internal elastic lamina causes mechanical instability and predisposes to dissection or distention at points of low resistance. Previously described clinical presentations of intracranial dissection in FMD have been mainly related to thromboembolic events or mass effects, including ataxia, tinnitus, loss of consciousness, deafness and facial paralysis.

Parent vessel occlusion, either surgical or endovascular, is the classical treatment [2]. In our patient, we preferred the stent-assisted coiling technique, which allows preservation of the parent vessel and complete occlusion of the pseudoaneurysm. The stent works as a scaffold for the coiling, preventing prolapse into the parent artery and permit- 
ting denser packing. The thrombogenicity of metal surfaces poses a risk of thrombosis within a stent, and its prevention includes aggressive antiaggregation therapy, usually with ASA (aspirin) and clopidogrel. However, this is controversial in the acute setting of subarachnoid hemorrhage. An alternative would be to start antiaggregation therapy after placement of the stent and first coil, and to treat possible stent thrombosis with abciximab.

A high rate of recurrence of dissecting aneurysms treated with this technique has been reported, presenting with either rebleeding or in follow-up angiography [3,4]. Recanalization is probably related to the disruption of all arterial layers, with the wall of the pseudoaneurysm composed only of fibrin and thrombus. For this reason, we used hydrocoils-bioactive coils that progressively expand, allowing denser packing than with standard platinum coils - thereby decreasing the possibility of recanalization [5]. The bioactive coil also favors endothelialization across the neck [6] of the treated aneurysm, thus contributing to the stable exclusion of the dissected aneurysm.

\section{References}

[1] Cloft HJ, Kallmes DF, Kallmes MH, Goldstein JH, Jensen ME, Dion JE. Prevalence of cerebral aneurysms in patients with fibromuscular dysplasia: a reassessment. J Neurosurg 1998;88: 436-40.

[2] Ahn JY, Han IB, Kim TG, Yoon PH, Lee YJ, Lee BH, et al. Endovascular treatment of intracranial vertebral artery dissections with stent placement or stent-assisted coiling. AJNR Am J Neuroradiol 2006;27:1514-20.

[3] Wakhloo AK, Mandell J, Gounis MJ, Brooks C, Linfante I, Winter J, et al. Stent-assisted reconstructive endovascular repair of cranial fusiform atherosclerotic and dissecting aneurysms long-term clinical and angiographic follow-up. Stroke 2008;39:3288-96.

[4] MacKay Cl, Han PP, Albuquerque FC, McDougall CG. Recurrence of a vertebral artery dissecting pseudoaneurysm after successful stent-supported coil embolization: case report. Neurosurgery 2003;53:754-61.

[5] Cloft HJ. HydroCoil for Endovascular Aneurysm Occlusion (HEAL) Study: periprocedural results. Am J Neuroradiol 2006;27:289-92.

[6] Kallmes DF, Fujiwara NH. New expandable hydrogel-platinum coil hybrid device for aneurysm embolization. AJNR Am J Neuroradiol 2002;23:1580-8.

M. Ribeiro ${ }^{a, *}$

J. Soares-Fernandes ${ }^{a}$

J. Rocha ${ }^{a}$

Á. Machado ${ }^{b}$

J. Cerqueira ${ }^{b}$

J. Moreira-Costac

J. Reis ${ }^{d}$

a Department of Neuroradiology, Hospital de-São-Marcos, Braga, Portugal

b Department of Neurology, Hospital de-São-Marcos, Braga, Portugal

' Department of Neurosurgery, Hospital de-São-Marcos, Braga, Portugal

' Department of Neuroradiology, Hospital de-São-José, Lisboa, Portugal
*Corresponding author. Hospital de-São-Marcos, Largo Engenheiro Carlos Amarante, Apartado 2242, 4701-965 Braga, Portugal.

E-mail address: manuelqr@portugalmail.pt (M. Ribeiro).

Available online 2 September 2009

doi:10.1016/j.neurad.2008.12.007

\section{L'angiopathie amyloïde: une cause oubliée d'hémorragie sous-arachnoïdienne}

\section{Cerebral amyloid angiopathy: A forgotten cause of sub-arachnoid hemorrhage}

Nous avons lu avec beaucoup d'intérêt la revue iconographique de Gauvrit et al. sur l'imagerie de l'hémorragie sous-arachnoïdienne (HSA) [1]. Les auteurs y rapportent la place prépondérante de l'imagerie non invasive dans le bilan étiologique de ces HSA, qu'elles soient dues à la rupture d'un anévrisme ou secondaires à une autre étiologie. Si l'article couvre parfaitement le premier cas de figure, il nous semble que les causes non anévrismales, celles qui en pratique peuvent poser de véritables problèmes diagnostiques, auraient pu être plus détaillées. Il nous semble même que certaines d'entre elles ont été oubliées dans cette revue. En effet, en dehors de quelques causes exceptionnelles que nous avions présenté lors du dernier congrès annuel de la SFNR [2], nous voulions rappeler ici que l'angiopathie amyloïde était une cause importante d'HSA isolée non traumatique du sujet âgé [3]. Bien que probablement sous diagnostiquées, ces HSA apparaissent pourtant stéréotypées, tant sur le plan clinique qu'en imagerie. Plus qu'une céphalée aiguë, ce sont principalement des manifestations épileptiques ou des déficits focaux transitoires qui font découvrir ces HSA [3]. Celles-ci sont également de diagnostic difficile sur le scanner cérébral réalisé en urgence, car l'hyperdensité est parfois à peine visible, comblant uniquement quelques sillons de la convexité (Fig. 1A). L'IRM permet de confirmer la présence de cette HSA sous forme d'un hypersignal des espaces sous-arachnoïdiens sur la séquence FLAIR, et surtout d'évoquer le diagnostic d'angiopathie amyloïde sur la séquence $T 2^{*}$, en révélant les classiques séquelles hémorragiques sus-tentorielles multiples épargnant les noyaux gris centraux (Fig. 1B et C). Enfin, il nous paraît fondamental de diagnostiquer ces HSA liées à l'angiopathie amyloïde car elles peuvent, dans certains cas, précéder la survenue d'hématomes intraparenchymateux cliniquement plus bruyant [4], comme nous l'illustrons dans le cas ci-dessous (Fig. 1).

\footnotetext{
Lettre à la rédaction en commentaire à l'article de Gauvrit et al. J Neuroradiol. 2009;36:65-73, publié en mai 2009.
} 